\title{
Neighbour relationship, community cohesion, crime cognition, and quality of life of older Taiwanese
}

Chih Ping Li, PhD

\begin{abstract}
Purpose. To measure the effects of community cohesion and crime cognition on overall quality of life (QOL) and its four domains (physical, psychological, social, and environmental) and to determine whether these effects are mediated by neighbour relationship among community-dwelling old adults.
\end{abstract}

Methods. A cross-sectional survey of 176 community-dwelling older Taiwanese and path analyses were conducted. Neighbour relationship was assessed using a 5-item, 5-point Likert scale; community cohesion using an 8-item, 5-point Likert scale; crime cognition using a 20-item, 10-point Likert scale; and QOL using the 28-item WHOQOL-BREF (Taiwan version). All were self-report questionnaires; higher scores indicated higher levels.

Results. Neighbour relationship as a mediator had a good fit in the four domains and overall QOL. The predictors (community cohesion and crime cognition) explained $23.3 \%$ of the variance in the physical domain, $30.7 \%$ in the psychological domain, 33.2\% in the social domain, $38.5 \%$ in the environmental domain, and $39.3 \%$ in the overall QOL. Community cohesion had a greater effect on four domains of QOL than crime cognition. The effect of community cohesion on QOL was largely directly rather than indirectly (through mediation by neighbour relationship).

Conclusion. Both community cohesion and crime cognition affect QOL of older adults. Neighbour relationship only mildly mediated community cohesion and crime cohesion.

Key words: Aged; Community participation; Crime; Quality of life

\section{ORIGINAL ARTICLE}

\author{
Department of Health Industry \\ Management, Kainan University, Taoyuan \\ City, Taiwan
}

Correspondence to: Chih Ping Li, Department of Health Industry Management, Kainan University, No.1 Kainan Road, Taoyuan 33857, Taiwan.

Email:luciali@mail.knu.edu.tw

\section{INTRODUCTION}

Increasing life expectancy is one of humanity's greatest accomplishments, ${ }^{1}$ but it is associated with population ageing. Maintaining quality of life (QOL) is one challenge of population ageing. According to the World Health Organization, QOL is defined as "an individual's perception of his/her position in life in the context of the culture and value systems in which he/she lives, and in relation to his/her goals, expectations, standards, and concerns". ${ }^{2}$ QOL involves both physical and psychological health and is determined by a number of factors. ${ }^{3}$

Neighbour relationship is one determinant of QOL and is associated with well-being, as its characteristics can modulate friendships and participation in social activities. ${ }^{4-6}$ Neighbourhood satisfaction is an indicator of social relationships (social contact, community dynamics, feeling of support, and positive orientation) and has considerable effects on QOL. ${ }^{7,8}$ In addition, total environmental factors of community cohesion and crime cognition are also determinants of QOL. ${ }^{9} 10$ 
According to collective efficacy theory, ${ }^{11}$ community cohesion among neighbours and the willingness to take action for the common good may improve QOL in older people. ${ }^{12}$ Community cohesion enables community leaders to effectively extract, combine, and activate resources, which can then be used to help members of the community to improve their physical, psychological, and social health. ${ }^{13}$ It may also enable realisation of common constructive values among its residents and maintenance of healthy social controls so as to decrease the level of violence within neighbourhood. Thus, community cohesion may improve QOL in community-dwelling older people by improving health and well-being and decreasing neighbourhood violence. Usually the association between community cohesion and QOL is stronger in older people. ${ }^{14}$ Nonetheless, urban dwellers have more neighbourhood problems than their rural counterparts who have more informal social support from neighbours. ${ }^{15}$ Both real and perceived measures of neighbourhood disorder are negatively related to QOL. ${ }^{12}$ Perception of neighbourliness partially acts as a buffer against the effects of neighbourhood distress, including housing foreclosures, on QOL.

Neighbourhood is one of the most common settings where residents forge attachments and create meaning, significance, and coherence in their lives. Resilient and stable neighbourhood is vital to the sustainability of healthy community. Residents who are satisfied with their neighbourhood report a greater sense of attachment to the local community, higher overall life satisfaction, greater political participation, and more likelihood to invest in building healthy and stable communities. ${ }^{12}$ Conversely, when community stability and sustainability are compromised, criminal activities within neighbourhood may increase. For instance, if residents migrate frequently, the community becomes unstable, leading to disintegration of mutual trust and group cohesion and making it difficult to sustain community development. ${ }^{16}$ When the community shows signs of deterioration, older community members may experience an increased fear of criminal activities. ${ }^{17} \mathrm{~A}$ fear of crime may cause older people to avoid certain individuals within the community who are perceived as dangerous. Reduced interactions with neighbours decrease the opportunity to interact in social events. Individuals who spend more time alone experience increased social isolation and decreased QOL. ${ }^{13,18}$

Neighbour relationship is a key factor influencing QOL in older people. ${ }^{19}$ It is also associated with community cohesion and crime cognition. To effectively measure QOL in older people, it is necessary to determine what factors have the greatest effect on QOL, and whether these factors are mediated by any variable. One study argued that neighbourhood problems were a weak moderator because previous studies focused on neighbourhood crime and disorder. ${ }^{15}$ Neighbourhood problems govern the type of interactions neighbours engage and may result in cordial relationships but inhibit development of intimate friendships and limit discussion. However, the impact of neighbourhood problems on QOL is unclear. Thus, this study aimed (1) to measure the effects of community cohesion and crime cognition on overall QOL and its four domains (physical, psychological, social, and environmental) and (2) to determine whether these effects are mediated by neighbour relationship among community-dwelling old adults. The researcher hypothesised that greater community cohesion and crime cognition correlated with higher QOL, and that neighbour relationship mediated the effects of community cohesion and crime cognition on QOL.

\section{METHODS}

This study was approved by the office of Research and Strategic Development of Kainan University (Ref.: KNU201213). Informed consent was obtained from each participant; participants were informed that participation was voluntary and that data collected would be used in research publications.

A purposive sample of community-dwelling Taiwanese aged $\geq 65$ years were recruited from a community in northern Taiwan between April and June 2011. Those with severe physical impairment or mental retardation were excluded. Data were collected through a face-to-face interview using a questionnaire.

Sociodemographic data including age, sex, marital status, education, religion, and living arrangement were collected. Independent variables were neighbour relationship, community cohesion, and crime cognition; these were developed by a 
dissertation on 995 residents in southern Taiwan. ${ }^{20}$ Scales of these variables performed very well in psychomatric tests. The fear of crime scale had a reasonable model fit in this sample in terms of relative Chi squared, comparative fit index (CFI), incremental fit index (IFI), and parsimony goodness of fit index (PGFI), although the Chi squared and the root mean square error of approximation (RMSEA) were below expectation. ${ }^{21}$

Neighbour relationship was assessed using a 5-item, 5-point Likert scale from strongly disagree (1) to strongly agree (5). Total scores ranged from 5 to 25; higher scores indicated better neighbour relationship; the internal consistency reliability was 0.724 .

Community cohesion was assessed using an 8-item, 5-point Likert scale from strongly disagree (1) to strongly agree (5). Total scores ranged from 8 to 40; higher scores indicated greater community cohesion; the internal consistency reliability was 0.977 .

The crime cognition score measured participants' evaluation of the seriousness of a crime. It was assessed using a 20-item, 10-point Likert scale from not at all serious (1) to very serious (10). Total scores ranged from 20 to 200; higher scores indicated higher level of crime cognition. Its internal consistency was high, with a Cronbach's alpha of 0.889 .

Quality of life was assessed using the 28item WHOQOL-BREF (Taiwan version) for physical, psychological, social relationships, and environmental domains. ${ }^{22,23}$ Scores for each item ranged from 1 (least favourable condition) to 5 (most favourable condition); total scores ranged from 28 to 140; higher scores indicated higher level of QOL. ${ }^{24}$

The two hypotheses were tested using a mediated path analysis. Neighbour relationship must correlate with both predictors (community cohesion and crime cognition) and outcome (each and overall domain of QOL) to be a mediator. The Sobel test was used to determine whether neighbour relationship was a mediator (with significant influence of an independent variable), and two-tailed probability values were used. ${ }^{25}$ The criteria for a good fit index was predefined: (1) a relative Chi squared criterion for acceptance of $<2$ to $<5,{ }^{26}$ (2) CFI of $>0.9,{ }^{27}$ (3) IFI of $>0.9,{ }^{26}$ (4) PGFI of $>0.5,{ }^{28}$ and (5) RMSEA of $\leq 0.05$ (0.05- 0.07 as an adequate fit, $0.08-0.10$ as a mediocre fit, and $>0.1$ as not acceptable). ${ }^{29}$ Data were analysed using PASW Statistics (Windows version 18.0; SPSS Inc, Chicago [IL], US) and AMOS 19.0 software.

\section{RESULTS}

Of 200 participants, four were excluded because of incomplete questionnaire and 176 (89 men and 87 women) aged 65 to 73 (mean, 70.73) years were analysed (TABLE $\mathbf{1}$ ).

Neighbour relationship as a mediator had a good fit in the physical domain $\left(\chi^{2}=3.067\right.$, $\mathrm{df}=1, \mathrm{p}=0.08, \mathrm{CFI}=0.976$, GFI $=0.91$, AGFI $=0.914$, $\mathrm{IFI}=0.978, \quad \mathrm{NFI}=0.967$, and RMSEA $=0.109 ;$ all paths $\mathrm{p}<0.05)$, psychological domain $\left(\chi^{2}=3.067\right.$, $\mathrm{df}=1, \mathrm{p}=0.08, \mathrm{CFI}=0.981$, GFI=0.991, AGFI=0.914, $\mathrm{IFI}=0.982, \mathrm{NFI}=0.973$, and RMSEA $=0.11$; all paths

TABLE 1

Demographics of participants $(n=176)$

\begin{tabular}{|c|c|}
\hline Variables & Value $^{\star}$ \\
\hline Age, y & $70.7 \pm 3.8$ \\
\hline \multicolumn{2}{|l|}{ Marital status } \\
\hline Unmarried & $79(44.9)$ \\
\hline Married & $97(55.1)$ \\
\hline \multicolumn{2}{|l|}{ Education } \\
\hline Illiterate & $52(29.5)$ \\
\hline Literate & $124(70.5)$ \\
\hline \multicolumn{2}{|l|}{ Religion } \\
\hline No & $16(9.1)$ \\
\hline Yes & $160(90.9)$ \\
\hline \multicolumn{2}{|l|}{ Living arrangement } \\
\hline Alone & $17(9.7)$ \\
\hline With others & 159 (90.3) \\
\hline Neighbour relationship & $9.06 \pm 2.07$ \\
\hline Community cohesion & $28.74 \pm 7.55$ \\
\hline Crime cognition & $141.82 \pm 19.43$ \\
\hline Quality of life & $53.13 \pm 8.20$ \\
\hline Physical domain & $11.83 \pm 1.72$ \\
\hline Psychological domain & $12.96 \pm 2.20$ \\
\hline Social domain & $14.22 \pm 2.60$ \\
\hline Environmental domain & $14.12 \pm 2.58$ \\
\hline
\end{tabular}

* Data are presented as mean \pm standard deviation or No. (\%) of participants 
TABLE 2

Decomposition of effects using path analysis

\begin{tabular}{|c|c|c|c|c|c|}
\hline Dependent variable & Independent variable & $\begin{array}{l}\text { Standardised coefficient } \\
\text { (95\% confidence interval) }\end{array}$ & $T$ & $\mathrm{p}$ Value & $R^{2}$ \\
\hline \multirow[t]{3}{*}{ Physical domain } & Community cohesion & $0.299(0.167-0.420)$ & 4.221 & $<0.001$ & 0.233 \\
\hline & Crime cognition & $0.238(0.088-0.356)$ & 3.466 & $<0.001$ & \\
\hline & Neighbour relationship & $0.173(0.015-0.356)$ & 2.366 & $<0.05$ & \\
\hline \multirow[t]{2}{*}{ Neighbour relationship } & Community cohesion & $0.344(0.176-0.514)$ & 5.039 & $<0.001$ & \\
\hline & Crime cognition & $0.254(0.100-0.387)$ & 3.710 & $<0.001$ & \\
\hline \multirow[t]{3}{*}{ Psychological domain } & Community cohesion & 0.379 (0.260-0.508) & 5.626 & $<0.001$ & 0.307 \\
\hline & Crime cognition & $0.271(0.154-0.393)$ & 4.154 & $<0.001$ & \\
\hline & Neighbour relationship & $0.161(-0.004-0.311)$ & 2.314 & $<0.05$ & \\
\hline \multirow[t]{2}{*}{ Neighbour relationship } & Community cohesion & $0.344(0.176-0.514)$ & 5.039 & $<0.001$ & \\
\hline & Crime cognition & $0.254(0.100-0.387)$ & 3.710 & $<0.001$ & \\
\hline \multirow[t]{3}{*}{ Social domain } & Community cohesion & $0.401(0.298-0.539)$ & 6.065 & $<0.001$ & 0.332 \\
\hline & Crime cognition & $0.163(0.026-0.296)$ & 2.542 & $<0.05$ & \\
\hline & Neighbour relationship & $0.241(0.072-0.373)$ & 3.528 & $<0.001$ & \\
\hline \multirow[t]{2}{*}{ Neighbour relationship } & Community cohesion & $0.344(0.176-0.514)$ & 5.039 & $<0.001$ & \\
\hline & Crime cognition & $0.254(0.100-0.387)$ & 3.710 & $<0.001$ & \\
\hline \multirow[t]{3}{*}{ Environmental domain } & Community cohesion & $0.424(0.300-0.560)$ & 6.684 & $<0.001$ & 0.385 \\
\hline & Crime cognition & $0.234(0.090-0.373)$ & 3.806 & $<0.001$ & \\
\hline & Neighbour relationship & $0.233(0.089-0.355)$ & 3.558 & $<0.001$ & \\
\hline \multirow[t]{2}{*}{ Neighbour relationship } & Community cohesion & $0.344(0.176-0.514)$ & 5.039 & $<0.001$ & \\
\hline & Crime cognition & $0.254(0.100-0.387)$ & 3.710 & $<0.001$ & \\
\hline \multirow[t]{3}{*}{ Overall quality of life } & Community cohesion & $0.426(0.318-0.549)$ & 6.766 & $<0.001$ & 0.393 \\
\hline & Crime cognition & $0.249(0.116-0.371)$ & 4.070 & $<0.001$ & \\
\hline & Neighbour relationship & $0.230(0.078-0.367)$ & 3.534 & $<0.001$ & \\
\hline \multirow[t]{2}{*}{ Neighbour relationship } & Community cohesion & $0.344(0.176-0.514)$ & 5.039 & $<0.001$ & \\
\hline & Crime cognition & $0.254(0.100-0.387)$ & 3.710 & $<0.001$ & \\
\hline
\end{tabular}

$\mathrm{p}<0.05)$, social domain $\left(\chi^{2}=3.067, \mathrm{df}=1, \mathrm{p}=0.08\right.$, CFI $=0.982, \quad$ GFI $=0.991 ， \quad$ AGFI $=0.914 ， \quad \mathrm{IFI}=0.982$, $\mathrm{NFI}=0.974$, and RMSEA $=0.109$; all paths $\mathrm{p}<0.05)$, environmental domain $\left(\chi^{2}=3.067, \mathrm{df}=1, \mathrm{p}=0.08\right.$, CFI $=0.984 ， \quad$ GFI $=0.991 ， \quad$ AGFI $=0.914 ， \quad I F I=0.984$, $\mathrm{NFI}=0.977$, and RMSEA $=0.109$; all paths $\mathrm{p}<0.05)$, and overall QOL $\left(\chi^{2}=3.067, \mathrm{df}=1, \mathrm{p}=0.08, \mathrm{CFI}=0.984\right.$, GFI=0.991, AGFI=0.914, IFI=0.985, NFI=0.978, and RMSEA=0.109; all paths $\mathrm{p}<0.001$ ).

In terms of the proportion of the variance explained in each QOL domain, the predictors (community cohesion and crime cognition) explained $23.3 \%$ of the variance in the physical domain, $30.7 \%$ in the psychological domain, $33.2 \%$ in the social domain, $38.5 \%$ in the environmental domain, and $39.3 \%$ in the overall QOL (TABLE 2 ).
Direct and indirect effects of community cohesion and crime cognition on the four domains and overall QOL are shown in the Figure. Community cohesion had a strong direct effect on the environmental domain and overall QOL (total effect=5.039), whereas crime cognition and neighbour relationship had a modest direct effect (TABLE 3). Community cohesion affected the environmental domain directly (0.42) and indirectly (through neighbour relationship) [0.08]. Similarly, crime cognition affected the environmental domain directly (0.23) and indirectly (0.06). The total effect of community cohesion and crime cognition on the environmental domain was 0.50 and 0.29 , respectively. The total effect of community cohesion, crime cognition, and neighbour relationship on overall QOL was 0.51, 0.31 , and 0.23 , respectively. Community cohesion 
(a)

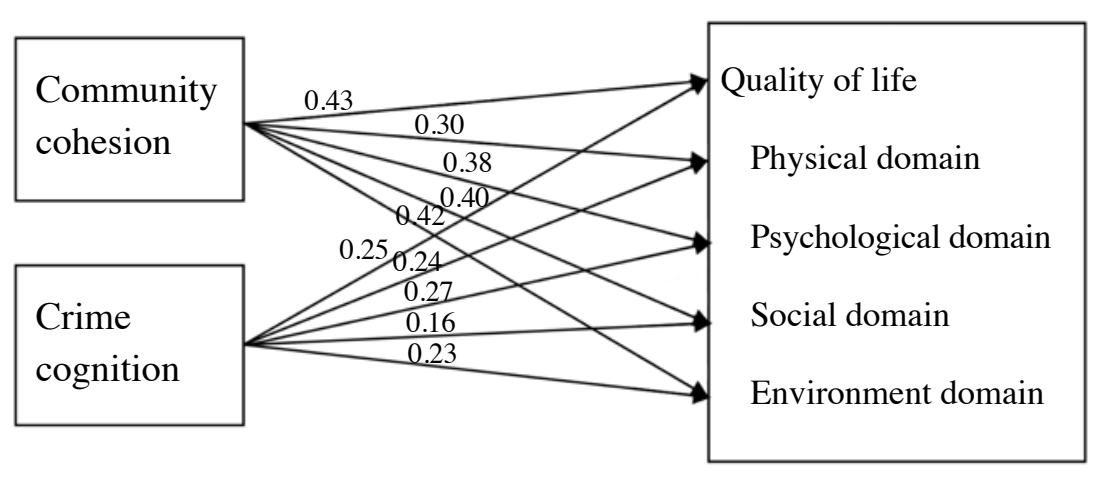

(b)

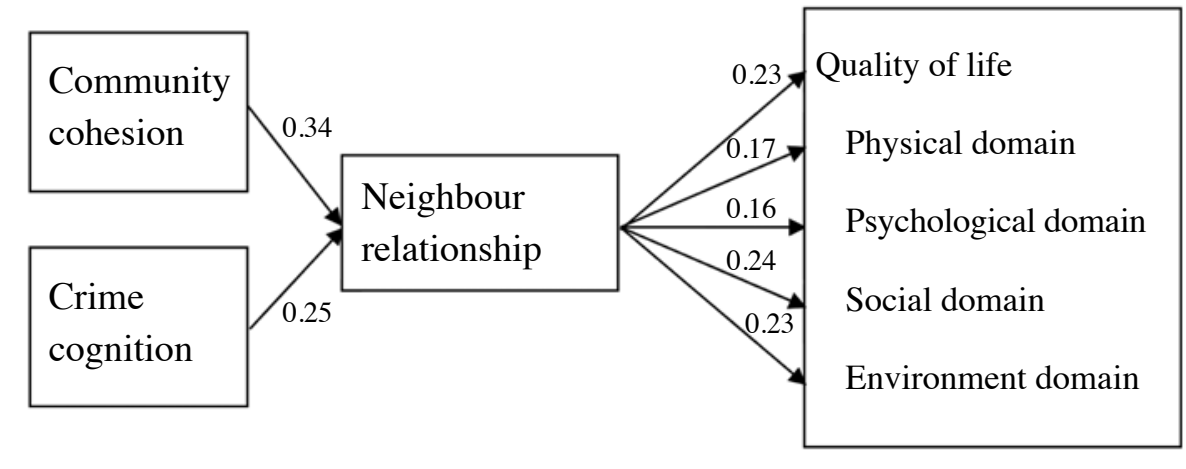

FigurE. (a) Direct and (b) indirect effects of community cohesion and crime cognition on four domains and overall quality of life.

affected overall QOL indirectly (0.09), which was significant among all indirect effects (through neighbour relationship).

\section{DISCUSSION}

Community cohesion had a greater direct effect on all four domains and overall QOL, compared with crime cognition and neighbour relationship, whereas crime cognition had a greater direct effect on the physical and psychological domains, compared with neighbour relationship. Community cohesion had the greatest direct effect on overall QOL than on any of the four domains. Neighbour relationship had a greater direct effect on the social domain than crime cognition. Neighbour relationship had a small indirect effect (through community cohesion and crime cognition) on all four domains and overall QOL, whereas community cohesion and crime cognition had a direct effect on neighbour relationship.

This study showed that community cohesion is important for improving QOL in community- dwelling older people. Older people who are aware of physical, psychological, social, or environmental issues of their neighbourhood may receive better care in the community. Neighbourhood is crucial to older people's sense of community ${ }^{30}$ and safety. Indeed, service or care provided by informal networks in the community may supplement informal care by family members or friends and even replace formal services to some degree. The association between care provided by family or friends and that by community-based health and personal social services has important consequences for QOL and policy (in terms of effectiveness, efficiency, equity, and cost containment).

The aetiological association between QOL and community cohesion is multifactorial. The greater collective efficacy in the community may be due to increased cohesion of its members. Community residents can accomplish more agreed-upon tasks if they foster common values and trusting relationships. Mutually beneficial human behaviours are promoted in the process of making common recreational areas safe for all. Close-knit communities promote 
TABLE 3

Direct and indirect effects on four domains and overall quality of life

\begin{tabular}{|c|c|c|c|}
\hline & Direct effect & Indirect effect & Total effect \\
\hline \multicolumn{4}{|l|}{ Physical domain } \\
\hline Community cohesion & 0.30 & 0.06 & 0.36 \\
\hline Crime cognition & 0.24 & $0.04(p<0.05)$ & 0.28 \\
\hline Neighbour relationship & 0.17 & - & 0.17 \\
\hline \multicolumn{4}{|l|}{ Neighbour relationship } \\
\hline Community cohesion & 0.34 & - & 0.34 \\
\hline Crime cognition & 0.25 & - & 0.25 \\
\hline \multicolumn{4}{|l|}{ Psychological domain } \\
\hline Community cohesion & 0.38 & $0.06(p<0.05)$ & 0.43 \\
\hline Crime cognition & 0.27 & $0.04(p<0.05)$ & 0.31 \\
\hline Neighbour relationship & 0.16 & - & 0.16 \\
\hline \multicolumn{4}{|l|}{ Neighbour relationship } \\
\hline Community cohesion & 0.34 & - & 0.34 \\
\hline Crime cognition & 0.25 & - & 0.25 \\
\hline \multicolumn{4}{|l|}{ Social domain } \\
\hline Community cohesion & 0.40 & $0.08(p<0.01)$ & 0.48 \\
\hline Crime cognition & 0.16 & $0.06(p<0.01)$ & 0.22 \\
\hline Neighbour relationship & 0.24 & - & 0.24 \\
\hline \multicolumn{4}{|l|}{ Neighbour relationship } \\
\hline Community cohesion & 0.34 & - & 0.34 \\
\hline Crime cognition & 0.25 & - & 0.25 \\
\hline \multicolumn{4}{|l|}{ Environmental domain } \\
\hline Community cohesion & 0.42 & $0.08(p<0.01)$ & 0.50 \\
\hline Crime cognition & 0.23 & $0.06(p<0.01)$ & 0.29 \\
\hline Neighbour relationship & 0.23 & - & 0.23 \\
\hline \multicolumn{4}{|l|}{ Neighbour relationship } \\
\hline Community cohesion & 0.34 & - & 0.34 \\
\hline Crime cognition & 0.25 & - & 0.25 \\
\hline \multicolumn{4}{|l|}{ Overall quality of life } \\
\hline Community cohesion & 0.43 & $0.09(p<0.01)$ & 0.51 \\
\hline Crime cognition & 0.25 & $0.02(p<0.01)$ & 0.31 \\
\hline Neighbour relationship & 0.23 & - & 0.23 \\
\hline \multicolumn{4}{|l|}{ Neighbour relationship } \\
\hline Community cohesion & 0.34 & - & 0.34 \\
\hline Crime cognition & 0.25 & - & 0.25 \\
\hline
\end{tabular}

healthy emotions among members. Older members expect to experience both mental and physical health advantages in such cohesive environment. ${ }^{31}$ Increasing community cohesion, knowledge of criminal activities, and trust in neighbourhood interactions was shown to directly improve the social and environment domains and overall QOL in community-dwelling older people.

Limitations of this study were: (1) the convenience sample from northern Taiwan may have resulted in selection bias; (2) the sample size was 
too small to be representative of the population or to generalise results; (3) data were self-reported and may have been biased because of selective memory and telescoping; and (4) using outcome measures from a dissertation may have reliability, concurrent, and construct validity problems. Nonetheless, the reliability was definitively established in communitydwelling older people. Changes of variables over time were not tracked; future research should include larger sample for long-term tracking. Quantitative analysis of a large amount of data in short period is not sufficient to measure complex human behaviour.

\section{CONCLUSION}

Both community cohesion and crime cognition affect QOL of older adults. Neighbour relationship only mildly mediated community cohesion and crime cohesion.

\section{REFERENCES}

1. World Health Organization. Active Ageing: a Policy Framework Geneva: World Health Organization; 2002. Available from: http://whqlibdoc.who.int/hq/2002/WHO_NMH_NPH_02.8.pdf. Accessed 2 March 2014.

2. World Health Organization Quality of Life Group. The Development of the World Health Organization Quality of Life Assessment Instrument (WHOQOL). In: Orley J, Kuyken W, editors. Quality of Life Assessment: International Perspectives: Berlin: Springer; 1994: 41-57. Crossref

3. Bowling A, Iliffe S. Psychological approach to successful ageing predicts future quality of life in older adults. Health Qual Life Outcomes 2011;9:13. Crossref

4. Dassopoulos A, Monnat SM. Do perceptions of social cohesion, social support, and social control mediate the effects of local community participation on neighborhood satisfaction? Environ Behav 2011;43:546-65. Crossref

5. Mair C, Diez Roux AV, Morenoff JD. Neighborhood stressors and social support as predictors of depressive symptoms in the Chicago Community Adult Health Study. Health Place 2010;16:811-9. Crossref

6. Berkman LF, Glass T. Social integration, social networks, social support, and health. Soc Epidemiol 2000;1:137-73.

7. Learmonth E, Taket A, Hanna L. Ways in which 'community' benefits frail older women's well-being: 'we are much happier when we feel we belong'. Australas J Ageing 2012;31:60-3. Crossref

8. Sun W, Aodeng S, Tanimoto Y, Watanabe M, Han J, Wang B, et al. Quality of life (QOL) of the community-dwelling elderly and associated factors: a population-based study in urban areas of China. Arch Gerontol Geriatr 2015;60:311-6. Crossref

9. Smith AE, Sim J, Scharf T, Phillipson C. Determinants of quality of life amongst older people in deprived neighbourhoods. Ageing Soc 2004;24:793-814. Crossref

10. Parra DC, Gomez LF, Sarmiento OL, Buchner D, Brownson $\mathrm{R}$, Schimd $\mathrm{T}$, et al. Perceived and objective neighborhood environment attributes and health related quality of life among the elderly in Bogotá, Colombia. Soc Sci Med 2010;70:1070-6. Crossref

11. Sampson RJ, Raudenbush SW, Earls F. Neighborhoods and violent crime: a multilevel study of collective efficacy. Science 1997;277:918-24. Crossref

12. Batson CD, Monnat SM. Distress in the desert: neighborhood disorder, resident satisfaction, and quality of life during the Las Vegas foreclosure crisis. Urban Aff Rev Thousand Oaks Calif 2015;51:205-38. Crossref

13. Hipp JR. Specifying the determinants of neighborhood satisfaction: a robust assessment in 24 metropolitan areas. Soc Forces 2009;88:395-424. Crossref

14. Elliott J, Gale CR, Parsons S, Kuh D ; HALCyon Study Team. Neighbourhood cohesion and mental wellbeing among older adults: a mixed methods approach. Soc Sci Med 2014;107:4451. Crossref

15. Nation M, Fortney T, Wandersman A. Race, place, and neighboring: social ties among neighbors in urban, suburban, and rural contexts. Environ Behav 2010;42:581-96. Crossref

16. Oh JH. Social bonds and the migration intentions of elderly urban residents: the mediating effect of residential satisfaction. Popul Res Policy Rev 2003;22:127-46. Crossref

17. Lorenc T, Clayton S, Neary D, Whitehead M, Petticrew M, Thomson $\mathrm{H}$, et al. Crime, fear of crime, environment, and mental health and wellbeing: mapping review of theories and causal pathways. Health Place 2012;18:757-65. Crossref

18. Sampson RJ. Local friendship ties and community attachment in mass society: a multi-level systemic model. Am Sociol Rev 1988;53:766-79. Crossref

19. Saito E, Sagawa Y, Kanagawa K. Social support as a predictor of health status among older adults living alone in Japan. Nurs Health Sci 2005;7:29-36. Crossref

20. Li SR. A study of the influence of the relationship among community, consciousness leisure participation and community cohesion of residents. Taichung, Taiwan: Chaoyang University of Technology; 2009.

21. $\mathrm{Li} \mathrm{CH}$. Exploring the gender difference in fear of crime among older people. Int J Manag Econ Soc Sci 2018;7:26-39.

22. Yao G. Development and Instruction of the WHOQOL-BREF and User's Manual. Taipei, Taiwan; 2000.

23. Yao G, Chung CW, Yu CF, Wang JD. Development and verification of validity and reliability of the WHOQOL-BREF Taiwan version. J Formos Med Assoc 2002;101:342-51.

24. The WHOQOL-Taiwan Group. The User's Manual of the Development of the WHOQOL-BREF Taiwan Version. Taipei, Taiwan; 2000.

25. MacKinnon DP, Fairchild AJ. Current directions in mediation analysis. Curr Dir Psychol Sci 2009;18:16. Crossref

26. Bollen KA. A new incremental fit index for general structural equation models. Sociol Methods Res 1989;17:303-16. Crossref

27. Bentler PM. Comparative fit indexes in structural models. Psychol Bull 1990;107:238-46. Crossref

28. Mulaik SA, James LR, Van Alstine J, Bennett N, Lind S, Stilwell CD. Evaluation of goodness-of-fit indices for structural equation models. Psychol Bull 1989;105:430-45. Crossref

29. Browne MW, Cudeck R. Alternative ways of assessing model fit. Sociol Methods Res 1992;21:230-58. Crossref

30. Li CH. Sense of community among inhabitants in Taiwan: an analysis of the systemic model. J City Plann 2010;37:209-31.

31. Tiernan C, Lysack C, Neufeld S, Lichtenberg PA. Community engagement: an essential component of well-being in older African-American adults. Int J Aging Hum Dev 2013;77:23357. Crossref 